\title{
Moderate rate of transmitted resistance mutations to antiretrovirals and genetic diversity in newly HIV-1 patients diagnosed in Benin
}

\author{
Edmond Tchiakpe ${ }^{1,2^{*}}$, Rene K. Keke ${ }^{1}$, Nicole Vidal ${ }^{3}$, Clément Ahoussinou ${ }^{4}$, Olga Sekpe ${ }^{1}$, Hermione G. Dagba ${ }^{1}$, \\ Eric Gbaguidi ${ }^{5}$, Conrad Tonoukouen ${ }^{5}$, Aldric Afangnihoun ${ }^{6}$, Moussa Bachabi ${ }^{5}$, Flore A. Gangbo ${ }^{5}$, \\ Halimatou Diop-Ndiaye ${ }^{7}$ and Coumba Toure-Kane ${ }^{7}$
}

\begin{abstract}
Objective: Seventeen years after the start of the IBAARV (Beninese initiative for access to antiretrovirals), transmitted drug resistance mutations in ARV-naïve patients and HIV-1 genetic diversity were investigated in Benin.

Results: Drug resistance mutations were detected in (27/248; 10.9\%) according to the WHO SDRM 2009 list, with a predominance of mutations directed against NNRTIs drugs (24/248; 10\%). Phylogenetic and recombination analyses showed a predominance of CRF02_AG strains (165/248; 66.5\%) and a high genetic diversity with five other variants and 39 URFs (15.7\%) which contained portions of strains that co-circulate in Benin. Eight recent transmission chains revealed active ongoing transmission of HIV-1 strains among ARV-naïve patients. Our study showed a moderate primary drug resistance mutations rate and also provided recent data on the HIV-1 variants that circulate in Benin. Regular monitoring of primary drug resistance is required to adapt HIV-1 treatment strategies and adoption of new WHO recommendations in Benin.
\end{abstract}

Keywords: HIV-1, Drug-resistance mutations, Genetic diversity, ARV naïve, Benin

\section{Introduction}

In 2019, about 37.9 million people were living with HIV that remains a major global public health problem [1]. Seven hundred seventy thousand people died from AIDS-related illnesses and 1.7 million people became newly infected with HIV despite the expansion of antiretroviral treatment (ART) programs in 2019 [1]. An undesired consequence of antiretroviral therapy expansion is the selection of mutations [2, 3] allowing viruses to become resistant to treatment. The timing

\footnotetext{
*Correspondence: tchiakpeedmond211170@gmail.com; edtchi@yahoo.fr ${ }^{1}$ National Reference Laboratory of Health Program Fighting Against AIDS in Benin (LNR/PSLS), Health Ministry of Benin, BP 1258, Cotonou, Benin
} Full list of author information is available at the end of the article of the introduction of ART treatment programs and non-adherence can be a proxy for higher levels of pretreatment drug resistance [4]. Transmission of these resistant viruses to therapy-naïve individuals could jeopardize the clinical benefits associated with ART [5] and the effectiveness of first-line ARV treatment. This leads to an increasing need for second-line treatment regimens whose reasons for its late start have been described by Murphy et al. [6]. Several studies reported variable rates of transmitted drug resistance ranging between 2 and $10.8 \%$ in resource-limited settings where ARTs were available $[7,8]$. In West Africa, rates of $8.3 \%$ and $10.8 \%$ were reported in Niger [9] and Togo [10] while rates of $4.2 \%$ and $8.2 \%$ were reported in Morocco [11] and Cameroon [12]. The rate of 3.9\% was reported

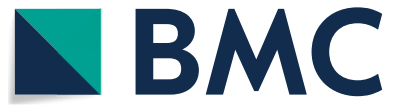

(c) The Author(s) 2020. This article is licensed under a Creative Commons Attribution 4.0 International License, which permits use, sharing, adaptation, distribution and reproduction in any medium or format, as long as you give appropriate credit to the original author(s) and the source, provide a link to the Creative Commons licence, and indicate if changes were made. The images or other third party material in this article are included in the article's Creative Commons licence, unless indicated otherwise in a credit line to the material. If material is not included in the article's Creative Commons licence and your intended use is not permitted by statutory regulation or exceeds the permitted use, you will need to obtain permission directly from the copyright holder. To view a copy of this licence, visit http://creativeco mmons.org/licenses/by/4.0/. The Creative Commons Public Domain Dedication waiver (http://creativecommons.org/publicdomain/ zero/1.0/) applies to the data made available in this article, unless otherwise stated in a credit line to the data. 
in Benin in 2012 [13]. To maximize the long-term effectiveness of first-line ART, WHO recommends that HIV treatment scale-up should always be accompanied by a robust assessment of drug resistance emergence and transmission (www.who.int/hiv/topics/drugresistance/ protocols/en/). One of the five keys of WHO HIV drug resistance monitoring and surveillance strategy is the surveillance of transmitted HIVDR in recently infected populations.

In Benin, HIV prevalence was $1.2 \%$ in general population in 2019. Benin reached 69-98-73 of 3X90 ONUSIDA goal and implemented a national strategy document for the care of the mother-child couple. This study reports 7 years after the first study [13] and after 17 years of ARV circulation in Benin, HIV drug-resistance mutations (DRM) and analyze whether the pattern of HIV-1 variants that circulate in Benin is stable over time in ARVnaive HIV-1 infected individuals.

\section{Main text}

Materials and methods

Study population

Samples (353) from antiretroviral-naïve HIV-1 infected individuals were studied. Samples were collected from October 2017 to December 2017 in nineteen health facilities care in the country (Fig. 1).

\section{Blood Sampling and Processing}

Blood samples were collected on EDTA tubes and RNA was extracted from plasma by using the QIAmp Viral RNA kit (Qiagen, Courtaboeuf, France) according to the manufacturer's instructions.

\section{Viral load, nested PCR amplification and sequencing}

Plasma HIV-1 RNA viral load (VL) was performed using Cobas $^{\circledR}$ TaqMan $^{\circledR}$ 96/Cobas ${ }^{\circledR}$ Ampliprep $^{\circledR}$ (CAP/CAP-CTM) HIV-1 quantitative assay (Roche

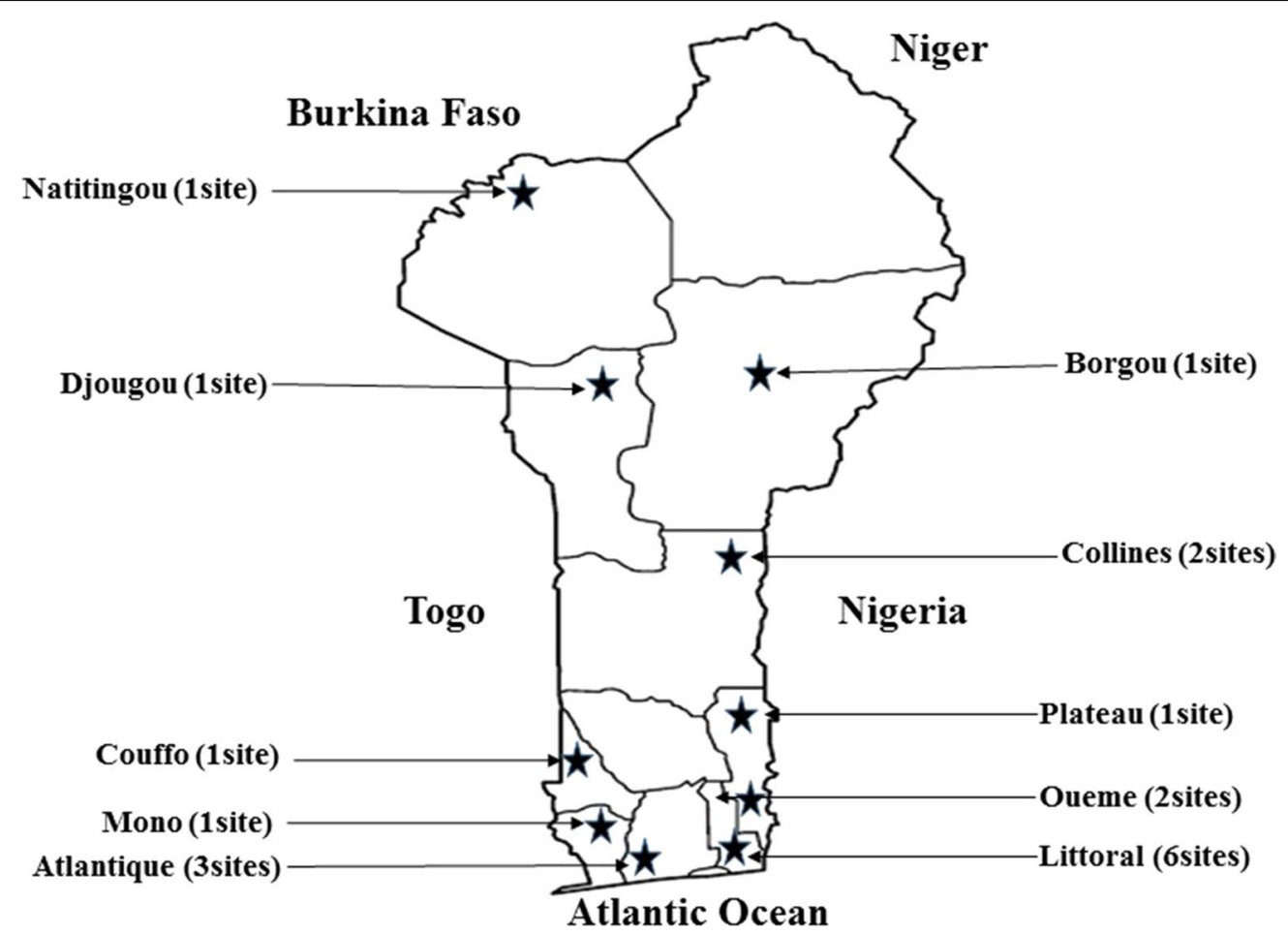

Fig. 1 Benin geographical map showing samples collection sites. Niger, Burkina Faso, Togo, Nigeria and Atlantic Ocean are bordering of Benin. * Represent the 10 departments hosting the collection sites out of 12 in Benin 
Molecular Diagnostics, Basel, Switzerland) in reference national laboratory fighting against AIDS in Benin (LNR/PSLS).

Nested PCR was performed in LNR/PSLS [14] on entire protease gene and at least the first 240 amino acids encoding the reverse transcriptase as previously described [11]. After amplification testing, 248 samples were eligible for HIV-1 drug resistance genotyping

PCR products were purified (Qiagen) and sequenced on AB 3500 Genetic Analyzer using Big Dye Terminator v3.1 (Applied Biosystems, Courtaboeuf, France) after cold precipitation. Sequences were edited online (https ://pssm.cfenet.ubc.ca/account/login) and translated into amino acid [15].

\section{Analysis of drug-resistance mutations}

Amino acid sequences were analyzed to determine the presence of mutations at positions known to be associated with drug resistance by using the latest (2009) version of the WHO list of mutations for surveillance studies [15].

\section{Phylogenetic analyses}

Generated sequences were aligned with reference sequences representing the overall genetic diversity of HIV-1 in West and Central Africa (available from Los Alamos HIV sequence database: http://hiv-web.lanl. gov/), by using MAFFT version 7 (https://mafft.cbrc. jp/alignment/server/) and G-Blocks to eliminate poorly aligned positions and divergent regions (molevol.cmima. csic.es/castresana/Gblocks_server). Phylogenetic tree reconstruction was done by the maximum likelihood method with the GTR + I+G model as implemented in Seaview v4.4.2 [16]. Besides, bootscanning analysis was done to explore any eventual mosaic structure for each strain with Simplot software and confirmed by phylogenetic analysis of the corresponding sub-segments in case of mosaic viruses [17].

Finally, recent transmission clusters were ascertained using the statistical robustness of ML topologies based on high bootstrap values (98\%) with 1000 re-samplings and short branch lengths following criteria previously defined [18].

Newly generated sequences were submitted to Genbank database under accession numbers: MT022598 to MT022684, MT022685 to MT022845 and MT022846 to MT023006.

\section{Ethics approval and consent to participate}

Ethical clearance was obtained from National Ethics Committee for Health Research. Written informed consent was obtained from each study participants

\section{Results}

\section{Characteristics of 248 study patients}

The median age was 38 years [IQR: 18-82] with $64.1 \%$ women and $35.9 \%$ men. Nearly $90 \%$ of patients were over 25 years of age and nearly $46 \%$ were married and living with a partner. Among patients, 4 were FSW and 8 were MSM. The median viral load was $5.12 \log 10$ [IQR: $2.20-7 \log 10]$.

\section{HIV DRM in antiretroviral naive patients in Benin}

DRM were detected in 27 of 248 (10.9\%) strains. Mutations associated with protease inhibitors (PIs), nucleoside reverse transcriptase inhibitors (NRTIs), non-nucleoside reverse transcriptase inhibitors (NNRTIs), and (NNRTIs + NRTIs) represented 1\% (2/248), 6\% (16/248), 10\% $(24 / 248)$, and $2 \%(5 / 248)$ respectively. Forty-two DRM have been identified (Table 1).

Two patients harbored each one protease mutation $(\mathrm{I} 85 \mathrm{~V}, \mathrm{n}=1)$ and $(\mathrm{L} 90 \mathrm{M}, \mathrm{n}=1)$.

The RT gene revealed mutations selected by thymidine analogs. One patient was infected with HIV-1 containing K65R and 19\% of naïve patients carried M184V $(n=8)$.

NNRTI and (NRTI+NNRTI) resistance mutations were detailed in Table 1.

\section{The distribution of 248 HIV-1 group M variants in Benin}

The phylogenetic tree analysis of 248 pol sequences is presented in Fig. 2. CRF02_AG predominated and represented [165/248 (66.5\%)] of the strains, followed in decreased order by CRF06_cpx [19/248 (7.7\%)], subtype G [16/248 (6.5\%)], sub-subtype A3 [6/248 (2.4\%)], A $[1 / 248(0.4 \%)], F[1 / 248(0.4 \%)]$. Moreover, $39 / 248$ (15.7\%) strains were unique recombinants (URFs), composed with strains that predominate or co-circulate in Benin: CRF02_AG, CRF06_cpx, G and A3.

\section{Identification of transmission clusters}

A maximum-likelihood phylogeny with 1000 bootstraps was inferred among thirty sample sequences suspected to share links (Additional file 1: Figure S1). Phylogenetic analysis evidenced eight recent transmission chains based on high bootstrap values (98\%) with 1000 re-samplings and very short branch lengths $(<0.015)$. Three other older transmission clusters were supposed with branch lengths values 0.016 and 0.018 (Additional file 1: Table S1).

\section{Discussion}

The study reports the presence of mutations in ARVnaive patients and genetic diversity of HIV-1 variants that circulate in Benin. Globally, the prevalence of transmitted drug resistance was $10.89 \%$ after 17 years of ARV 
Table 1 HIV-1 Subtypes and Antiretroviral Drug Mutations in Twenty-Seven Beninese-Naive Patients

\begin{tabular}{|c|c|c|c|c|c|c|c|}
\hline \multirow[t]{2}{*}{ Samples ID } & \multirow[t]{2}{*}{ Age (years) } & \multirow{2}{*}{$\begin{array}{l}\text { Viral } \\
\text { load } \\
\left(\log _{10}\right)\end{array}$} & \multicolumn{4}{|c|}{ Drug Resistance Mutations Associated } & \multirow[t]{2}{*}{ HIV-1 subtypes } \\
\hline & & & $\mathrm{PI}^{*}$ & NRTI* & NNRTI* & NRTI+ NNRTI* & \\
\hline Ben148 & 31 & 5.52 & - & - & K103N & - & URF (CRF02_AG/A3) \\
\hline Ben 784 & 34 & 4.31 & - & - & K103N & - & CRF02_AG \\
\hline Ben 538 & 42 & 5.81 & - & M184V & - & - & G \\
\hline Ben 169 & 33 & 6.2 & - & - & G190A & - & URF (CRF06_cpx/A) \\
\hline Ben 18 & 36 & 5.04 & $185 \mathrm{~V}$ & - & - & - & CRF02_AG \\
\hline Ben 226 & 35 & 5.7 & - & - & K103N & - & A3 \\
\hline Ben 230 & 25 & 5.37 & - & - & K103N & - & CRF02_AG \\
\hline Ben 232 & 20 & 6.57 & - & M184V & - & - & URF (CRF02_AG/A1) \\
\hline Ben 255 & 30 & 5.39 & - & - & K103N & - & CRF02_AG \\
\hline Ben 722 & 29 & 5.28 & - & D67N & K103N & D67N, K103N & CRF02_AG \\
\hline Ben 607 & 40 & 3.45 & - & M184V & V106A, G190A & M184V, V106A, G190A & G \\
\hline Ben 96 & 31 & 5.85 & L90M & - & - & - & CRF02_AG \\
\hline Ben 98 & 43 & 4.97 & - & - & $\mathrm{K} 103 \mathrm{~N}$ & - & CRF06_cpx \\
\hline Ben 687 & 28 & 5.28 & - & M41L & $\mathrm{K} 103 \mathrm{~N}$ & M41L, K103N & URF (CRF06_cpx/CRF02_AG) \\
\hline Ben 420 & 25 & 631 & - & M184V & - & - & URF (CRF06_cpx/CRF02_AG/A3) \\
\hline Ben 643 & 20 & 5.54 & - & - & Y188L & - & CRF02_AG \\
\hline Ben 657 & 42 & 5.6 & - & $\mathrm{T} 215 \mathrm{~S}$ & - & - & CRF02_AG \\
\hline Ben 206 & 41 & 5.27 & - & - & K103N, P225H & - & CRF02_AG \\
\hline Ben 208 & 26 & 4.99 & - & M184V & - & - & CRF02_AG \\
\hline Ben 211 & 51 & 4.31 & - & - & K103N & - & CRF02_AG \\
\hline Ben 212 & 35 & 4.18 & - & K65R, M184I & K103N, Y188L & K65R, M184I, K103N, Y188L & CRF02_AG \\
\hline Ben 213 & 35 & 5.58 & - & M184V & Y181C & M184V, Y181C & G \\
\hline Ben 214 & 45 & 5.97 & - & - & K103N & - & CRF02_AG \\
\hline Ben 216 & 37 & 6.68 & - & M184V & - & - & URF (CRF02_AG/U) \\
\hline Ben 218 & 52 & 5.06 & - & - & $\mathrm{K} 103 \mathrm{~N}$ & - & A3 \\
\hline Ben 390 & 52 & 5.67 & - & - & K103N & - & CRF02_AG \\
\hline Ben 101 & 45 & 5.39 & - & $\begin{array}{c}\text { D67G, K70R, } \\
\text { M184V } \\
\text { K219Q }\end{array}$ & V106M, Y181C, G190A & $\begin{array}{l}\text { D67G, K70R, M184V, K219Q } \\
\text { V106M, Y181C, G190A }\end{array}$ & G \\
\hline
\end{tabular}

NRTI nucleoside reverse transcriptase inhibitors, NNRTI nonnucleoside reverse transcriptase inhibitors, PI protease inhibitors, URF unique recombinant forms, Ben Benin *According to the WHO algorithm for Surveillance of Drug Resistance Mutations (SDRM), 2009

circulation in the country, that is consistent with results from other African countries [10, 19-21]. But, studies from some other Sub-Saharan countries have reported rates lower than $10 \%$, by using the same WHO standard protocol and the WHO list of resistance mutations for epidemiological surveys [22, 23]. HIV-1 drug resistance mutations were known to be one of the major factors limiting the effectiveness of ARVs. In our study, the mutations encountered were those associated with the ARVs used in first-line treatment since the start of IBAARV in 2002.

This first-line treatment used two NRTIs (zidovudine/stavudine (AZT/D4T) + lamivudine (3TC)) plus an NNRTI [nevirapine/efavirenz (NVP/EFV)], as well as non-boosted protease inhibitor (indinavir) regimens [24]. At that time, virologic monitoring was not available and patients were followed based on clinical signs and CD4 counts [25]. Moreover, those who were in therapeutic failure stayed long periods with ineffective treatment, leading to an accumulation of resistance mutations [26]. This accumulation of resistance mutations may compromise the effectiveness of second-line drugs [27] and increases the risk of transmission of drug-resistant strains to naïve patients [10]. Among naïve patients in our study, 27 already harbored at least one drug resistance mutations and the NNRTIs represent $10 \%$ while the NRTIs and PIs represent $6 \%$ and $1 \%$ respectively.

NRTIs resistance-associated mutations were present in sixteen patients. M184V was the predominant NRTI encountered which confers resistance to 3TC. The K65R confers resistance to abacavir (ABC) and tenofovir (TDF). Thymidine-associated mutations (TAMs) 


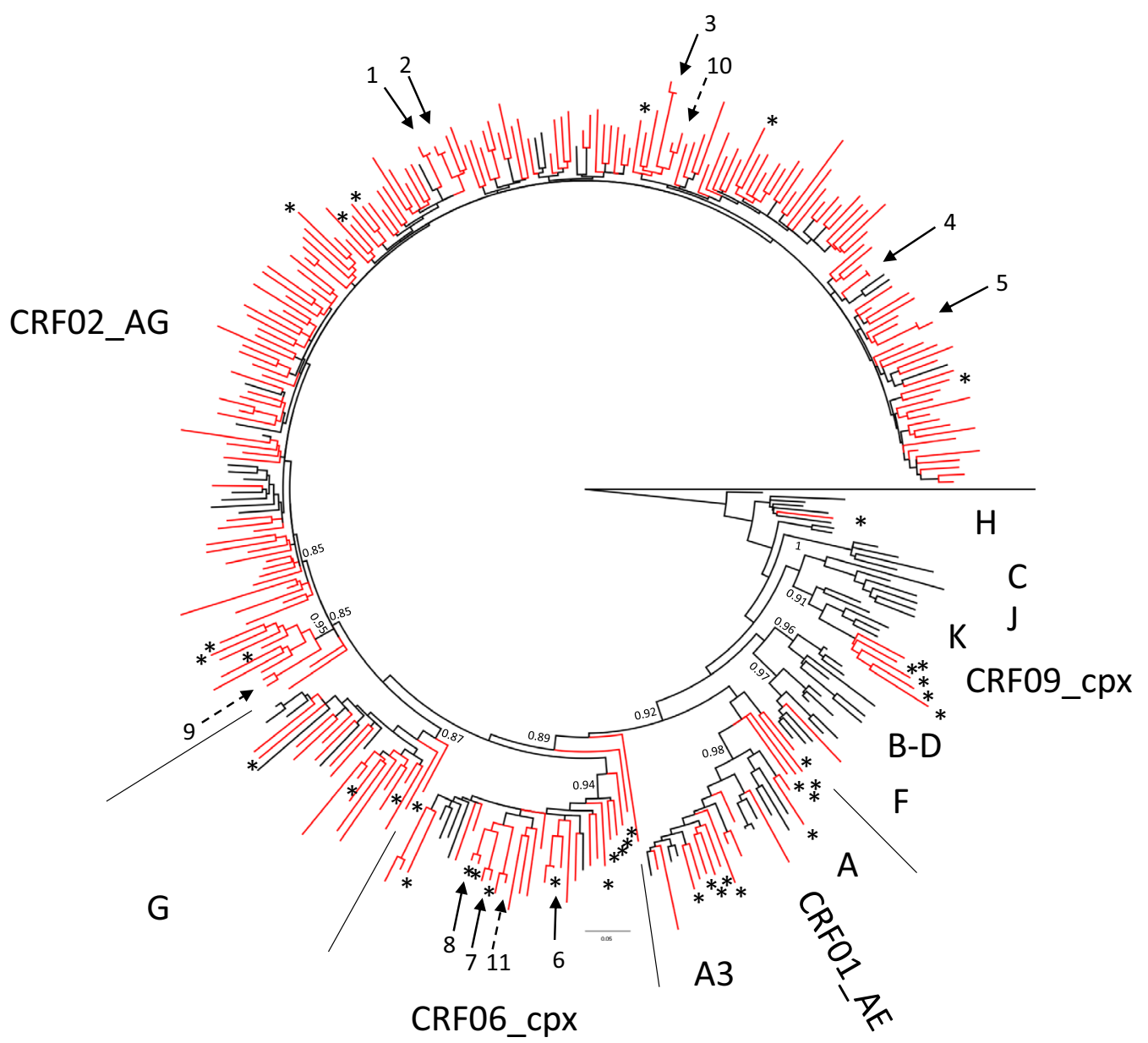

Fig. 2 Maximum likelihood tree for 248 HIV-1-infected drug-naive patients in Benin. The length of the alignment was 656 unambiguously aligned nucleotides in the reverse transcriptase region of the pol gene. Circulating recombinant forms (CRFs) and sub-subtypes not represented within the sequences genomic structure were excluded. Reference sequences are in black and patient sequences are in red. Unique recombinants over protease and RT are shown with an asterisk. An arrow indicates the sample sequences involved into recent transmission chains $(n=8)$, older supposed transmission chains are indicated with a broken arrow $(n=3)$, and the clusters were numbered. Branch support values are indicated for the major key nodes

were found but only one patient in our study harbored at least two TAMs conferring intermediate resistance to zidovudine (AZT). TAMs M41L, T215S have been described in Togo $[10,21]$ and also in Burkina Faso with D67N and K219Q [21]. K70R observed in one case in our study was also found in Guinea-Conakry [23]. For non-adherence reasons to treatment, M184IV is quickly selected in patients under 3TC which explains its presence in high proportion in studies of transmitted resistance $[22,23]$. The high predominance of $\mathrm{M} 184 \mathrm{~V}$ could also mean that these individuals are not naive due to the infrequent transmission of this mutation, which is due to its high fitness. Lamivudine is also given to HBV infected individuals or individuals co-infected with HIV and HBV. Since the study was conducted after the time of TDF use (replacing D4T as recommended by $\mathrm{WHO}$ ), the presence of $\mathrm{K} 65 \mathrm{R}$ in patients could easily be explained.

The major mutations associated to NNRTIs were K103N (33\%) encountered in fourteen patients which compromise the effectiveness of NNRTIs first generation (NVP and EFV) and G190A (7\%) identified in three patients which compromise NVP, EFV and etravirine [28]. The high prevalence of the K103N mutation could be explained by its transmission capacity similar to that of wild-type viruses and may be present for years in infected individuals [29-31]. This mutation is also the most common in women who receive a single dose of $\mathrm{NVP}$ for the prevention of mother-to-child transmission [32, 33]. In fact, approximately $64.1 \%$ of study participants were women and some of them could be part 
of PMTCT programs. These mutations associated with high-level resistance have been described in one and four patients in Togo and Conakry [10, 23] respectively in naïve patients. The others mutations excepting Y181C and Y188L detected in two cases were V106A, P225H, and V106M, each detected in one case.

Two people exhibited each one mutation associated to PIs (I85V, $\mathrm{n}=1$ ) and (L90M, $\mathrm{n}=1$ ). In our study, no patient harboured both mutations which conferred intermediate resistance to atazanavir.

Globally, the presence of these mutations could be explained by the wide use of Triomune at the start of IBAARV in Benin [24].

Phylogenetic analysis evidenced eight recent and three probable older transmission chains $(6.5-8.9 \%$ of the study patients), reflecting active ongoing transmission. Interestingly, eight patients reported as being MSM and from them, two were involved into the same transmission chain, in which one patient came from Togo and the second one was from Benin. This situation was described in Dakar where the subtype C predominating in the MSM group is increasing in the general population [34, 35], confirming the existence of a dual epidemic in the country. In our study we did not find any transmission chain involving both population groups individual, however, the number of MSM patients is too low to conclude. Further studies are needed in key groups to assess whether HIV-1 strains from MSM intermix with those from the general population in Benin or with those from other countries.

CRF02_AG predominated with $66.5 \%$ rate confirming the stability of genetic diversity in 2011 [24] and 2012 [13]. Overall, the genetic diversity in Benin matches with results found in a neighboring country, Togo [10]. The other strains (CRF06_cpx, subtype $G$ and sub-subtype A3) have been also reported in other neighbouring African countries [9, 22, 36]. Regarding the unique recombinants (URFs), their proportion among different regions have changed over time [37]. The rate observed in our study $(15.7 \%, 39 / 248)$ is fully concordant with the proportion from West Africa [37] and is not significantly different from that was observed in Togo $(22.9 \%, 19 / 83)$ $(p=0.27)$. These URFs being composed of predominant or co-circulating strains, demonstrate the existence of frequent dual infections with at least two strains of HIV-1 [38] in the country.

The study documents the moderate prevalence of transmitted drug resistance of HIV-1 in Benin, and active ongoing transmission of HIV-1 strains circulating usually in West Africa.

\section{Limitations}

Our study has certain limits. Patients who reported being naive may have been on ART and have previously harbored resistant viruses because they were included based on self-reported information. Moreover, the number of patients recruited is higher in the south of country than the north.

\section{Supplementary information}

Supplementary information accompanies this paper at https://doi. org/10.1186/s13104-020-05151-w.

Additional file 1: Figure S1. Phylogenetic analysis of transmission chains. Maximum likelihood tree with 1000 bootstrap resamplings for 30 sample sequences (in red). Bootstrap values are indicated on the branches and clusters are numbered. Table S1. Branch lengths for each cluster or sequences pair indicated in the tree of Figure S1.

\section{Abbreviations}

IBAARV: Beninese initiative for access to antiretrovirals; CNERS: National Ethics Committee for Health Research; ARV: Antiretroviral; Pol: Polymerase; RT: Reverse transcriptase; WHO: World Health Organization; Pb: Base pairs; CD4: Cluster of differentiation 4; DRM: Drug-resistance mutations; SDRM: Surveillance Drug Resistance Mutation; URF: Unique recombinant form; CRF: Circulating Recombinant forms; ART: Antiretroviral Treatment; HIV: Human Immunodeficiency Viruse; HIVDR: Human Immunodeficiency Viruse Drug Resistance; EDTA: Ethylenediaminetetraacetic; RNA: Ribonucleic acid; TAMs: Thymidineassociated mutations; VL: Viral Load; ANRS: National Agency for Research on AIDS and Viral Hepatitis; MAFFT: Multiple sequence alignment based on fast Fourier transform; PCR: Polymerase Chain Reaction; IQR: Interquartile; NNRTI: Non-nucleoside reverse transcriptase inhibitor; NRTI: Nucleoside reverse transcriptase inhibitor; PI: Protease inhibitor; MSM: Men having sex with Men; FSW: Female sex worker; AZT: Zidovudine; SQV: Saquinavir; IDV: Indinavir; NFV: Nelfinavir; FSP: Fosamprenavir; TPV: Tripanavir; LPV: Iopinavir; ATV: atazanavir; RPV: Rilpivirine; DOR: Doravirine; ABC: Abacavir; TDF: Tenofovir; EFV: Efavirenz; NVP: Nevirapine; ETR: Etravirine; A: Alanine; C: Cysteine; D: Acide aspartique; E: Acide glutamique; F: Phenylalanine; G: Glycine; H: Histidine; I: Isoleucine; K: Lysine; L: Leucine; M: Methionine; N: Asparagine; P: Proline; Q: Glutamine; R: Arginine; S: Serine; T: Threonine; V: Valine; W: Tryptophane; Y: Tyrosine.

\section{Acknowledgements}

We thank Ministry of Health in Benin for providing authorizations to conduct the study. We also thank the physicians responsible for the 19 patients care sites included in the study

\section{Authors' contributions}

OS, HGD performed the viral load assays. ET performed the viral load assays, genotypic drug-resistance testing, interpretation and drafted the manuscript. NV wrote the manuscript and ensured the quality control of the sequences. CA perform statistical Analysis. RKK, EG, CT, MB, FAG conception of study, participated in its design and coordination. AA enrolled patients and collected of samples. HDN, CTK wrote the manuscript. All authors read and approved the final manuscript.

\section{Funding}

The data collection process has been funded by Global Fund. The funding body played no role in the design, data collection, analysis and writing of the manuscript.

\section{Data availability}

All the raw data generated are available upon reasonable request to corresponding author

Ethics approval and consent to participate

Ethical clearance was obtained from National Ethics Committee for Health Research (CNERS): number 33 of august 09, 2017. Written informed consent 
was obtained from each study participants. Confidentiality and anonymity of the information was also maintained.

\section{Consent for publication}

Not applicable

\section{Competing interests}

The authors declare that they have no competing interests.

\section{Author details}

${ }^{1}$ National Reference Laboratory of Health Program Fighting Against AIDS in Benin (LNR/PSLS), Health Ministry of Benin, BP 1258, Cotonou, Benin. ${ }^{2}$ Laboratory of Cell Biology and Physiology, Department of Biochemistry and Cellular Biology, Faculty of Sciences and Technology (FAST) and Institute of Applied Biomedical Sciences (ISBA), University of Abomey-Calavi, 01, BP 918 Cotonou, Benin. ${ }^{3}$ UMI233-TransVIHMI, IRD (Institut de Recherche pour le développement), U1175 (INSERM) et Université de Montpellier, Montpellier, France. ${ }^{4}$ Epidemiologist, Socio-anthropologist, Consulting, Cotonou, Benin. ${ }^{5}$ Health Program Fighting Against AIDS in Benin (PSLS), Health Ministry of Benin, Cotonou, Benin. ${ }^{6}$ Centre de Traitement Ambulatoire de I'Hôpital de zone de Suru Léré, Cotonou, Benin. ${ }^{7}$ Institute for Health Research, Epidemiological Surveillance and Training of Senegal, Dakar, Senegal.

Received: 18 April 2020 Accepted: 24 June 2020

Published online: 02 July 2020

\section{References}

1. Onusida. www.unaids.org/sites/default/files/media_asset/UNAIDSFact Sheet_fr.pdf. 2019.

2. Kantor R, Shafer RW, Follansbee S, Taylor J, Shilane D, Hurley L, Nguyen DP, Katzenstein D, Fessel WJ. Evolution of resistance to drugs in HIV1-infected patients failing antiretroviral therapy. AIDS. 2004;1811:1503-11.

3. Novak RM, Chen L, MacArthur RD, Baxter JD, Huppler Hullsiek K, Peng G, Xiang Y, Henely C, Schmetter B, Uy J, van den Berg-Wolf M, Kozal M. Prevalence of antiretroviral drug resistance mutations in chronically HIV-infected, treatment-naive patients: implications for routine resistance screening before initiation of antiretroviral therapy. Clin Infect Dis. 2005;403:468-74.

4. Hamers RL, Wallis CL, Kityo C, Siwale M, Mandaliya K, Conradie F, Botes ME, Wellington M, Osibogun A, Sigaloff KC, Nankya I, Schuurman R, Wit FW, Stevens WS, van Vugt M, de Wit TF. HIV-1 drug resistance in antiretroviral-naive individuals in sub-Saharan Africa after rollout of antiretroviral therapy: a multicentre observational study. Lancet Infect Dis. 2011;1110:750-9.

5. Mbange AE, Kaba D, Diouara AAM, Diop-Ndiaye H, Ngom-Ngueye NF, Dieng A, Lo S, Toure KN, Fall M, Mbacham WF, Diallo MS, Cisse M, Mboup $\mathrm{S}$, Kane CT. Surveillance of transmitted HIV-1 antiretroviral drug resistance in the context of decentralized HIV care in Senegal and the Ebola outbreak in Guinea. BMC Res Notes. 2018:111:723.

6. Murphy RA, Court R, Maartens G, Sunpath H. Second-line antiretroviral therapy in sub-saharan africa: it is time to mind the gaps. AIDS Res Hum Retroviruses. 2017;3312:1181-4.

7. Hamers RL, Derdelinckx I, van Vugt M, Stevens W, de Wit TF, Schuurman R. The status of HIV-1 resistance to antiretroviral drugs in sub-Saharan Africa. Antiviral therapy. 2008;135:625-39.

8. Aghokeng AF, Vergne L, Mpoudi-Ngole E, Mbangue M, Deoudje N, Mokondji E, Nambei WS, Peyou-Ndi MM, Moka JJ, Delaporte E, Peeters M. Evaluation of transmitted HIV drug resistance among recently-infected antenatal clinic attendees in four Central African countries. Antiviral Ther. 2009;143:401-11.

9. Mamadou S, Hanki Y, Ali Maazou AR, Aoula B, Diallo S. Genetic Diversity and Drug Resistance Mutations in HIV-1 from Untreated Patients in Niamey, Niger. ISRN Microbiol. 2011;2011:797463.

10. Yaotse DA, Nicole V, Roch NF, Mireille PD, Eric D, Martine P. Genetic characterization of HIV-1 strains in Togo reveals a high genetic complexity and genotypic drug-resistance mutations in ARV naive patients. Infect Genet Evol. 2009;94:646-52.

11. Bakhouch K, Oulad-Lahcen A, Bensghir R, Blaghen M, Elfilali KM, Ezzikouri S, Abidi O, Hassar M, Wakrim L. The prevalence of resistance-associated mutations to protease and reverse transcriptase inhibitors in treatmentnaive (HIV1)-infected individuals in Casablanca, Morocco. J Infect Dev Countr. 2009;35:380-91.

12. Ceccarelli L, Salpini R, Moudourou S, Cento V, Santoro MM, Fokam J, Takou D, Nanfack A, Dori L, Torimiro J, Sarmati L, Andreoni M, Perno CF, Colizzi $\checkmark$, Cappelli $G$. Characterization of drug resistance mutations in naive and ART-treated patients infected with HIV-1 in Yaounde, Cameroon. J Med Virol. 2012;845:721-7.

13. Chamberland A, Diabate S, Sylla M, Anagounou S, Geraldo N, Zannou DM, Labbe AC, Worobey M, Alary M, Tremblay C. Transmission of HIV-1 drug resistance in Benin could jeopardise future treatment options. Sexually Trans Infect. 2012;883:179-83.

14. Diouara AA, Diop-Ndiaye H, Kebe-Fall K, Tchiakpe E, Ndiaye O, Ayouba A, Peeters M, Mboup S, Kane CT. Dried blood spots for HIV-1 drug resistance genotyping in decentralized settings in Senegal. J Med Virol. 2014:861:45-51.

15. Bennett DE, Camacho RJ, Otelea D, Kuritzkes DR, Fleury H, Kiuchi M, Heneine W, Kantor R, Jordan MR, Schapiro JM, Vandamme AM, Sandstrom P, Boucher CA, van de Vijver D, Rhee SY, Liu TF, Pillay D, Shafer RW. Drug resistance mutations for surveillance of transmitted HIV-1 drug-resistance: 2009 update. PLOS ONE. 2009;43:e4724.

16. Gouy M, Guindon S, Gascuel O. SeaView version 4: a multiplatform graphical user interface for sequence alignment and phylogenetic tree building. Mol Biol Evol. 2010;272:221-4.

17. Lole KS, Bollinger RC, Paranjape RS, Gadkari D, Kulkarni SS, Novak NG, Ingersoll R, Sheppard HW, Ray SC. Full-length human immunodeficiency virus type 1 genomes from subtype C-infected seroconverters in India, with evidence of intersubtype recombination. J Virol. 1999:731:152-60.

18. Hue S, Clewley JP, Cane PA, Pillay D. HIV-1 pol gene variation is sufficient for reconstruction of transmissions in the era of antiretroviral therapy. AIDS. 2004;185:719-28.

19. Keita A, Sereme Y, Pillet S, Coulibaly S, Diallo F, Pozzetto B, Thiero TA, Bourlet T. Impact of HIV-1 primary drug resistance on the efficacy of a first-line antiretroviral regimen in the blood of newly diagnosed individuals in Bamako, Mali. J Antimicrob Chemother. 2019;741:165-71.

20. Haidara A, Chamberland A, Sylla M, Aboubacrine SA, Cisse M, Traore HA, Maiga MY, Tounkara A, Nguyen VK, Tremblay C. High level of primary drug resistance in Mali. HIV Med. 2010;116:404-11.

21. Tebit DM, Sangare L, Tiba F, Saydou Y, Makamtse A, Somlare H, Bado G, Kouldiaty BG, Zabsonre I, Yameogo SL, Sathiandee K, Drabo JY, Krausslich $\mathrm{HG}$. Analysis of the diversity of the HIV-1 pol gene and drug resistance associated changes among drug-naive patients in Burkina Faso. J Med Virol. 2009;8110:1691-701.

22. Maiga Al, Fofana DB, Maiga AC, Diallo F, Ait-Arkoub Z, Daou F, Cisse M, Sarro YD, Oumar AA, Sylla A, Katlama C, Taiwo B, Murphy R, Tounkara A, Marcelin AG, Calvez V. Transmitted antiretroviral drug resistance in newly HIV-infected and untreated patients in Segou and Bamako, Mali. AIDS Res Human Retroviruses. 2013;291:182-6.

23. Charpentier C, Bellecave P, Cisse M, Mamadou S, Diakite M, Peytavin G, Tchiombiano S, Teisseire P, Pizarro L, Storto A, Brun-Vezinet F, Katlama C, Calvez V, Marcelin AG, Masquelier B, Descamps D. High prevalence of antiretroviral drug resistance among HIV-1-untreated patients in GuineaConakry and in Niger. Antiviral Ther. 2011;163:429-33.

24. Monleau FF, Affolabi D, Afangnihoun A, Boillot F, Anagonou S, Peeters $\mathrm{M}$, Delaporte E. Antiretroviral drug resistance in HIV-1 infected patients receiving antiretroviral treatment in routine clinics in Cotonou, Benin. J AIDS HIV Res. 2011:36:114-20.

25. Gilks CF, Crowley S, Ekpini R, Gove S, Perriens J, Souteyrand Y, Sutherland D, Vitoria M, Guerma T, De Cock K. The WHO public-health approach to antiretroviral treatment against HIV in resource-limited settings. Lancet. 2006;3689534:505-10.

26. Sturmer M, Dauer B, Moesch M, Haberl A, Mueller A, Locher L, Knecht G, Hanke N, Doerr HW, Staszewski S. Evolution of resistance mutations during low-level viral replication in HIV-1-infected patients treated with zidovudine/lamivudine/abacavir as a first-line regimen. Antiviral Ther. 2007;121:25-30.

27. Hosseinipour MC, Gupta RK, Van Zyl G, Eron JJ, Nachega JB. Emergence of HIV drug resistance during first- and second-line antiretroviral therapy in resource-limited settings. J Infect Dis. 2013;207(Suppl 2):S49-56. 
28. Annemarie M. Wensing M, PhD; Vincent Calvez, MD, PhD; Francesca Ceccherini-Silberstein, PhD; Charlotte Charpentier, PharmaD, PhD; Huldrych F. Günthard, MD; Roger Paredes, MD, PhD; Robert W. Shafer, MD; Douglas D. Richman, MD. Update of the Drug Resistance Mutations in HIV-1. 2019; 273.

29. Wertheim JO, Kosakovsky Pond SL, Forgione LA, Mehta SR, Murrell B, Shah S, Smith DM, Scheffler K, Torian LV. Social and genetic networks of HIV-1 transmission in New York City. PLoS Pathog. 2017;131:e1006000.

30. Kuhnert D, Kouyos R, Shirreff G, Pecerska J, Scherrer AU, Boni J, Yerly S, Klimkait T, Aubert V, Gunthard HF, Stadler T, Bonhoeffer S. Quantifying the fitness cost of HIV-1 drug resistance mutations through phylodynamics. PLoS Pathog. 2018;142:e1006895.

31. Castro H, Pillay D, Cane P, Asboe D, Cambiano V, Phillips A, Dunn DT. Persistence of HIV-1 transmitted drug resistance mutations. J Infect Dis. 2013;2089:1459-63.

32. Coovadia H. Current issues in prevention of mother-to-child transmission of HIV-1. Curr Opin HIV AIDS. 2009;44:319-24.

33. Flys TS, Donnell D, Mwatha A, Nakabiito C, Musoke P, Mmiro F, Jackson JB, Guay LA, Eshleman SH. Persistence of K103N-containing HIV-1 variants after single-dose nevirapine for prevention of HIV-1 mother-to-child transmission. J Infect Dis. 2007;1955:711-5.

34. Ndiaye HD, Tchiakpe E, Vidal N, Ndiaye O, Diop AK, Peeters M, Mboup S, Toure-Kane C. HIV type 1 subtype C remains the predominant subtype in men having sex with men in Senegal. AIDS Res Hum Retroviruses. 2013;299:1265-72.
35. Ndiaye HD, Toure-Kane C, Vidal N, Niama FR, Niang-Diallo PA, Dieye T, Gaye-Diallo A, Wade AS, Peeters M, Mboup S. Surprisingly high prevalence of subtype $C$ and specific HIV-1 subtype/CRF distribution in men having sex with men in Senegal. J Acquir Immune Defic Syndr. 2009;522:249-52.

36. Diop-Ndiaye H, Toure-Kane C, Leye N, Ngom-Gueye NF, Montavon C, Peeters M, Mboup S. Antiretroviral drug resistance mutations in antiretroviral-naive patients from Senegal. AIDS Res Hum Retroviruses. 2010;2610:1133-8.

37. Hemelaar J, Elangovan R, Yun J, Dickson-Tetteh L, Fleminger I, Kirtley S, Williams B, Gouws-Williams E, Ghys PD. Global and regional molecular epidemiology of HIV-1, 1990-2015: a systematic review, global survey, and trend analysis. Lancet Infect Dis. 2019;192:143-55.

38. Baldrich-Rubio E, Anagonou S, Stirrups K, Lafia E, Candotti D, Lee H, Allain JP. A complex human immunodeficiency virus type $1 \mathrm{~A} / \mathrm{G} / \mathrm{J}$ recombinant virus isolated from a seronegative patient with AIDS from Benin, West Africa. J Gen Virol. 2001;82(5):1095-106.

\section{Publisher's Note}

Springer Nature remains neutral with regard to jurisdictional claims in published maps and institutional affiliations.
Ready to submit your research? Choose BMC and benefit from:

- fast, convenient online submission

- thorough peer review by experienced researchers in your field

- rapid publication on acceptance

- support for research data, including large and complex data types

- gold Open Access which fosters wider collaboration and increased citations

- maximum visibility for your research: over $100 \mathrm{M}$ website views per year

At BMC, research is always in progress.

Learn more biomedcentral.com/submissions 